\title{
The epidemiology of norovirus gastroenteritis in China: disease burden and distribution of genotypes
}

\author{
Honglu Zhou ${ }^{1, *}$, Songmei Wang ${ }^{2, *}$, Lorenz von Seidlein ${ }^{3,4}$, Xuanyi Wang $(\bowtie)^{1,5}$ \\ ${ }^{I}$ Key Laboratory of Medical Molecular Virology of MoE \& MoH, and Institutes of Biomedical Sciences, Fudan University, Shanghai 200032 , \\ China; ${ }^{2}$ Laboratory of Molecular Biology, Training Center of Medical Experiments, School of Basic Medical Sciences, Fudan University, \\ Shanghai 200032, China; ${ }^{3}$ Mahidol-Oxford Tropical Medicine Research Unit, Faculty of Tropical Medicine, Mahidol University, Bangkok \\ 10400, Thailand; ${ }^{4}$ Centre for Tropical Medicine and Global Health, Nuffield Department of Medicine, University of Oxford, Oxford OX1 \\ 2JD, UK, ${ }^{5}$ Children's Hospital, Fudan University, Shanghai 200032, China
}

(C) The Author(s) 2019. This article is published with open access at link.springer.com and journal.hep.com.cn

\begin{abstract}
With the improvements of sanitation and nationwide safe water supply the occurrence of bacterial diarrhea declined remarkably, while viruses became the leading causes of acute gastroenteritis (AGE). Of these viruses, noroviruses (NoVs) are responsible for a considerable burden of gastroenteritis, especially in children $<2$ years and elderly $\geqslant 65$ years. NoVs circulating in the Chinese population are antigenically highly diverse with the genotype GII.4 being the dominant strain followed by GII.3. Given the widespread contamination in environmental sources, and highly infectious nature of NoVs, vaccination would be the desirable strategy for the control of $\mathrm{NoV}$ infections. However, a better understanding of acquired immunity after infection, and a reliable immunological surrogate marker are urgently needed, since two vaccine candidates based on virus-like particles (VLPs) are currently moving into clinical evaluations in China.
\end{abstract}

Keywords molecular epidemiology; norovirus; disease burden; genotype; China

\section{Introduction}

Despite significant advances in sanitation improvement, safe water supplies, and vaccination, diarrheal disease remained worldwide the fourth most frequent cause of death for children $<5$ years of age in 2016 [1]. Globally, noroviruses (NoVs) was associated with approximately one-fifth of all diarrhea cases [2]. Young children experienced the highest incidence of disease, while severe outcomes were most common among young children and the elderly [3]. Despite the extensive diversity of NoVs, a single genotype (GII.4) is most prevalent in humans worldwide $[4,5]$. In China, according to the National Notifiable Infectious Disease Reporting (NIDR) system, 1275290 cases of infectious diarrhea were reported in 2017 (excluding cholera, dysentery, and enteric fever), resulting in an incidence of 92.2/100 000 person/year [6]. Among 9.3 percent of infectious diarrhea cases with

Received July 16, 2019; accepted October 31, 2019

Correspondence: Xuanyi Wang, xywang@shmu.edu.cn

${ }^{*}$ Honglu Zhou and Songmei Wang contributed equally to this work. laboratory confirmed pathogens, viral infections were responsible for $91.0 \%$ [7]. NoVs play an increasingly important role in the etiology of diarrhea in China [8].

$\mathrm{NoV}$ is a non-enveloped, small RNA virus that contains a single stranded, positive-sense, polyadenylated RNA genome. It has an icosahedral shape with a diameter of about $38 \mathrm{~nm}$. The genome is approximately $7.4-7.7 \mathrm{~kb}$ in length and consists of three open reading frames (ORFs). ORF1 encodes six non-structural proteins, including RNAdependent RNA polymerase (RdRp), which plays a major role in NoV replication in host cells. ORF2 is approximately $1.8 \mathrm{~kb}$ in length and encodes the major structural protein, VP1, including the highly conserved inner domain ( $\mathrm{S}$ domain) and the protruding domain ( $\mathrm{P}$ domain). The $\mathrm{P}$ domain consists of a stem-like, moderately conserved P1 subdomain and a surface-exposed, hypervariable P2 subdomain, thus determining the antigenicity and cell binding of the virus [9]. ORF3 is approximately $0.6 \mathrm{~kb}$ in length, encoding a $22 \mathrm{kDa}$ small structural protein VP2, may be related to forming of a portal-like channel through the capsid for delivering viral genome into host cells [10]. NoV genotyping showed that the virus has high genetic and antigenic diversity, including five gene groups, of 
which GI and GII groups are mainly related to humans, with 9 and 22 genotypes, respectively [11].

NoVs are highly infective for a range of reasons. First, the minimum infectious dose is less than 10 copies of the virus [12]. Second, the infected person has a long virus shedding period [13], and even continues to be infectious after the clinical symptoms disappear. Third, NoVs are robust and can survive on dry surfaces for several weeks [14]. Finally, NoVs spread by the fecal-oral route, including contaminated water sources, food, and contaminated surfaces [15]. The incubation period is $24-48 \mathrm{~h}$ with $12 \mathrm{~h}$ the shortest and $72 \mathrm{~h}$ the longest reported incubation period. Children present with vomiting and diarrhea while adult patients tend to present with diarrhea alone. The course of the disease is self-limiting and patients usually recover in 2 to 3 days. There are currently no specific antiviral drugs against NoVs and treatment is mainly supportive.

\section{Epidemiology}

\section{Disease burden}

Since acute gastroenteritis (AGE) caused by NoVs is not a notifiable disease in China, the incidence of NoVs cannot be obtained directly from the currently available national statistics. There is also no systematic research into NoV episodes using satisfactory representative sampling. Data from three sources can be used to estimate the NoV specific burden in China: (1) hospital-based sentinel surveillance for diarrhea, (2) retrospective cross-sectional population-based surveys used worldwide for the prevalence of AGE [16], and (3) individual population-based viral AGE surveillance.

A systematic review extracted and synthesized the prevalence of community-based all-cause AGE obtained from the published literatures, and based on NoVs detection rates extrapolated the incidence of NoV AGE [8]. Surprisingly, the estimated NoV incidence for China in 2015 reached 6.0 (95\% confidence interval [CI]: 4.7-7.6) per 100 person per year for the entire population with the highest incidence in children less than 5 years of age, 15.6 (95\% CI: 9.1-23.2) per 100 children per year [8]. Between 2012 and 2013, an incidence of 8.9 cases (95\% CI: 8.29.7) per 100 per year for all age groups, with a highest incidence of 20.3 (95\% CI: 13.8-27.9), and 14.7 (95\% CI: 9.2-20.8) per 100 per year in children aged 0-11 months and 12-23 months respectively, was estimated in Shanghai based on hospital sentinel surveillance [17]. Further evidence comes from abovementioned independent systems. An incidence of 4.7-11.7 per 100 per year in children aged 6-11 months and 4.0-6.6 per 100 per year in children 12-17 months were determined from a population-based surveillance conducted in Zhengding County, Hebei
Province and Sanjiang County, Guangxi Zhuang Autonomous Region between 2011 and 2013 [18]. These findings suggest that considerable disease burden is caused by NoV in China. Due to the exclusion of disease episodes which present with vomiting only from nearly all studies, the published data underestimate the actual NoV burden in China.

\section{Population at risk}

Identification of populations at risk for transmission is always crucial for disease control and vaccine development. Children less than 2 years of age are at the highest risk for NoV AGE, followed by young adults and a middle age population ( $20-50$ years), and the elderly $(\geqslant 65$ years) based on sentinel surveys for diarrhea in hospitals and the routine community-based cross-section surveys for AGE [8]. The proportion of AGE caused by NoVs found in a nationwide diarrhea survey in hospitals was $13.7 \%(95 \%$ CI: $13.1 \%-14.3 \%$ ), $8.7 \%$ (95\% CI: $7.5 \%-9.9 \%$ ), $11.7 \%$ (95\% CI: $11.1 \%-12.3 \%$ ), and $12.3 \%$ (95\% CI: $11.0 \%-$ $13.7 \%$ ) in 6-23 months, 24-59 months, 25-64 years, and elderly ( $\geqslant 65$ years), respectively [19]. A typical age distribution of rotavirus AGE in children $<5$ years was also concluded from a population-based NoV AGE surveillance. The incidence was $4.7-11.7$ cases, $4.0-6.6$ cases, 2.5-2.9 cases, $1.3-1.9$ cases and $<1.0$ cases per 100 children per year in children aged 6-11 months, $12-17$ months, 18-23 months, 24-29 months and $\geqslant 30$ months, respectively [18]. Moreover, the severity of illness caused by NoVs is similar to that induced by rotavirus infection [18].

Hospital-based prospective, community-based retrospective and population-based prospective AGE surveillance found that the incidence of NoVAGE decreased with age from 3 to 24 years. The majority $(\sim 80 \%)$ of NoVs outbreaks reported to the Chinese Public Health Emergency Event Surveillance System (PHEESS) occurred in older children attending kindergartens, primary schools, and secondary schools [20]. The character of the immunity acquired after NoVs infections remains incompletely understood. The current understanding, that NoVs infections confers immunity for 6 months and 2 years comes from human challenge studies, which fails to explain the low incidence of NoV related disease in this population. Children have more opportunities to become exposed to NoVs through direct and indirect contact with other children recorded in the reports of outbreaks, in addition to the sporadic transmission. Thus, a longer persistence can probably be expected than was estimated in the challenge study. Several recent published modeling studies have estimated that immunity against NoVs lasts from 4 to 8 years post-infection [21].

In China, not only young children but also people $\geqslant 65$ years of age are at an increased risk for NoV AGE. More 
than $10 \%$ NoVs outbreaks were reported from nursing homes and medical institutions for the elderly in the past years in China [22]. A systematic review of 102 NoVs outbreaks from 2003 to 2013 in China, found the highest attack rate $68 \%$ in hospitalized elderly patients [23]. A multivariate analysis found the risk of a NoV AGE episode increased with increasing need of nursing support (Odds Ratio $=1.40,95 \%$ CI: 1.03-1.91) [24]. In addition, studies from the United States indicating that, compared to hospitalized children, hospitalized elderly with NoVs infection were more commonly admitted to the intensive care unit (ICU) (36\% vs. $7 \%, P=0.02)$ [25], and resulted in a 10-fold higher case fatality rate in elderly than in children [26]. China is entering an era of an aging society. The elderly ( $\geqslant 65$ years) accounted for $>20 \%$ of entire population in Shanghai in 2017 [27]. As the consequence of the one-child policy, the traditional home-based care model is no longer realistic in many parts of China, more and more elderly people need to live in nursing homes, and NoV infections will present a serious challenge for public health in China in the future.

AGE remains an unmet concern in military forces. Outbreaks due to NoVs infection have been reported in many countries, for instance, an outbreak involving 450 cases of AGE occurred on a US Naval aircraft carrier in 1997 [28]. AGE outbreaks have been reported in British [29], French [30], Singapore [31] and Chinese [32] military units. NoVs illness is generally mild, characterized by acute vomiting and diarrhea lasting for couple of days, but can be severe when soldiers are exhausted and dehydrated, eventually leading to their diminished operational effectiveness.

\section{Seasonality}

Although the distribution of NoV AGE varies between regions, it is believed to be associated with heavy rainfall, low temperature, and high humidity in mathematical models [33]. Although NoV AGE can occur throughout the year, historically, NoV AGE has been considered a "winter vomiting disease" [34]. In general, more NoV infections are detected during the colder season (October throughout March). This trend was not significant in the provinces in the south of China $[8,19]$. The incidence of NoVs infection is remarkably low in the Qinghai-Tibet Plateau located in south-west of China [19], probably related to the low humidity in the region. Similar to sporadic NoV AGE, the majority of outbreaks have occurred in the colder season $[8,19,20,23,35]$.

\section{Genotype diversity}

From the nationwide diarrhea survey in hospitals, between
2009 and 2013, 34031 diarrhea cases were reported from 173 sentinel hospitals, with $3878 \mathrm{NoV}$ infections. Of these, $3484(89.8 \%)$ cases were caused by genogroup II viruses, and only $394(10.2 \%)$ cases infected by genogroup I viruses [19]. Although GI, GII, and GIV NoVs can attack humans, GII is the predominant virus group circulating in China. To understand the genetic diversity and temporal distribution of NoV circulating in China, all available NoVs gene sequences isolated from human host were downloaded from the NCBI GenBank Database by searching the corresponding taxonomy ID of NoVs (Taxonomy ID: 142786) with a keyword "China." As of May 24, 2016, in total, $3134 \mathrm{NoV}$ sequences detected in China were analyzed. Only GI and GII viruses were detected, which accounted for $13.1 \%$ (411) and $86.9 \%$ (2723), respectively. Overall, 12 GI genotypes and 18 GII genotypes were identified. The most common genotype was GII.4 (1571; 50.1\%), followed by GII.17 (343; 10.9\%) and GII.3 (240; 7.7\%), other common genotypes included GI.2 (108; 3.4\%), GII.12 (107; 3.4\%), GII.e (104; 3.3\%), GII.6 (99; $3.2 \%)$, GI.3 (70; $2.2 \%)$, GI.5 (65; $2.1 \%)$, GI.1 $(51 ; 1.6 \%)$, GI.4 (44; 1.4\%), GII.13 (39; $1.2 \%)$, and GII.21 $(37 ; 1.2 \%)$ (Table 1) [36].

Due to the preferential reporting of outbreaks and emerging strains, the distribution of genotype summarized from those GenBank's sequences might not be representative of the real genotype distribution in the population. For instance, GII.17 had been an emergent strain causing a number of outbreaks in China in 2014 and 2015. It spread rapidly since 2013 , from an initial $4.0 \%$ to $79.6 \%$ in 2015 , and eventually accounted for $10.9 \%$ of GenBank sequences. To eliminate the potential bias due to overreporting of outbreak strains, a meta-analysis was conducted which included reports published before January 2017, which found the most common genotype was GII.4 (49.7\%), followed by GII.3 (9.5\%) and GII.17 (8.4\%), other common genotypes included GII.12 (2.4\%), GI.2 (2.3\%), GI.4 (1.8\%), GI.3 (1.7\%), GII.13 (1.7\%), GII.6 (1.5\%), and GI.5 (1.4\%) (Table 1) [8].

Population-based surveillance in children $<5$-year conducted in Zhengding and Sanjiang County between 2011 and 2013 found a similar genotype distribution. In Zhengding, the predominant genotype were GII.3 (32.5\%) and GII.4 (30.0\%), followed by GII.2 (7.5\%) and GII.6 (2.5\%); in Sanjiang, majority infection were caused by GII.6 (39.3\%) and GII.4 (37.7\%), followed by GII.7 (4.9\%) and GII.17 (3.3\%) (Table 1) [18].

NoV genotypes vary with time, region, and age group but the epidemic genotype did not change frequently in China. Since the late 1990s, a single genotype (GII.4) of NoVs has been dominant. Six variants of GII.4 have emerged during the period. The most prevalent variants were Den Haag_2006b in 2006-2011, New Orleans 2009 in 2009-2011, and Sydney_2012 in 2012-2015; the other 
Table 1 Genotypes distribution of norovirus by study design in China

\begin{tabular}{|c|c|c|c|c|}
\hline \multirow[b]{2}{*}{ Genotype } & \multicolumn{4}{|c|}{ Sources of data and study design } \\
\hline & $\begin{array}{l}\text { GenBank } \\
\text { (hospital-based and outbreaks surveys) } \\
(\%)\end{array}$ & $\begin{array}{l}\text { Meta-analysis } \\
\text { (hospital-based surveys) } \\
(\%)\end{array}$ & $\begin{array}{l}\text { Zhengding } \\
\text { (population-based surveillance) } \\
(\%)\end{array}$ & $\begin{array}{l}\text { Sanjiang } \\
\text { (population-based surveillance) } \\
(\%)\end{array}$ \\
\hline GI.1 & 1.6 & 0.6 & - & - \\
\hline GI.2 & 3.4 & 2.3 & - & - \\
\hline GI.3 & 2.2 & 1.7 & - & - \\
\hline GI.4 & 1.4 & 1.8 & 0.6 & - \\
\hline GI.5 & 2.1 & 1.4 & - & - \\
\hline GI.6 & 0.7 & 1.3 & - & - \\
\hline GI.7 & 0.1 & 1.3 & - & - \\
\hline GI.8 & 0.8 & 0.8 & - & - \\
\hline GI.9 & 0.2 & - & - & 1.6 \\
\hline GII.1 & 0.1 & 2.8 & - & - \\
\hline GII.2 & 0.9 & 0.8 & 7.5 & - \\
\hline GII.3 & 7.7 & 9.5 & 32.5 & - \\
\hline GII.4 & 50.1 & 49.7 & 30.0 & 37.7 \\
\hline GII.5 & 0.1 & 2.4 & - & - \\
\hline GII.6 & 3.2 & 1.5 & 2.5 & 39.3 \\
\hline GII.7 & 0.7 & 0.4 & 0.6 & 4.9 \\
\hline GII.8 & 0.03 & 0.5 & - & - \\
\hline GII.10 & - & 0.8 & - & - \\
\hline GII.11 & - & 1.7 & - & - \\
\hline GII.12 & 3.4 & 2.4 & - & - \\
\hline GII.13 & 1.2 & 1.7 & - & - \\
\hline GII.14 & 0.2 & 0.4 & - & - \\
\hline GII.15 & 0.1 & 0.6 & - & - \\
\hline GII.16 & 0.1 & 0.5 & - & - \\
\hline GII.17 & 10.9 & 8.4 & - & 3.3 \\
\hline GII.18 & - & 0.6 & - & - \\
\hline GII.21 & 1.2 & 0.4 & - & - \\
\hline GII.22 & 0.03 & 0.8 & - & - \\
\hline Others & 7.46 & 2.8 & 26.3 & 13.1 \\
\hline
\end{tabular}

three minor variants were Asia 2003 in 2004-2005, Hunter 2004 in 2004-2005, and Apeldoorn 2007 in 2009, respectively [37]. New GII.4 strains emerge almost every 2-4 years, and associated with an increased NoVs activity. It is noteworthy that, in addition to GII.4, a novel variant of GII.17 and a recombinant variant of GII.2 (GII. P16/GII.2) had a wide distribution between 2014 and 2015 and $2016-2017$, respectively [38-41].

\section{Contaminated food and other environmen- tal sources for NoV infections}

NoVs illness is commonly contracted through contaminated food, water and person-to-person transmission. NoVs have been detected in shellfish [42,43], lettuce, strawberries [44], river water [45], sewage [46], and environmental samples [47] in the past years. Despite concerted efforts to improve food safety, the food- and water-borne outbreaks continue, since some products, including salads and shellfish are typically eaten raw or only lightly cooked.

China possess 45 coastal fishing regions between Liaoning Province in the North to Hainan Province in the South. To get a better understanding of the contamination of economically important shellfish with human enteric viruses, a study was conducted which investigated samples from the abovementioned 45 regions. Contaminated shellfish were detected in all regions, with an average detection rate of $14.8 \%$ (24/162). No significant difference in detection rate was observed between the coastal fishing regions. Of 6 shellfish groups (clams, oysters, mussels, razor clams, blood clams, and scallops), oysters had the 
highest detection rate $(35 \%)$ of NoVs, followed by blood clams (22\%) [43]. These results suggest that uncooked seafood is a potential public health hazard in China.

Studies have established a close correlation between seafood, aquaculture water, sewage, river water, and AGE. A study conducted in Guangdong Province explored the effect of seasonality of the detection rates. During winter and spring more NoVs were detected in aquaculture water (20.0\%), seafood (50.0\%) and human AGE patients (20.7\%), compared to summer and autumn $(6.2 \%, 10.9 \%$ and $17.6 \%$ ) (Fig. 1), though the seasonality in patients did not reach statistical significance [48]. Phylogenetic analyses suggests that homologous NoV genotypes circulate between human populations, seafood and aquaculture water [48]. This suggestion is supported by studies conducted in Guangdong Province. For instance, 19.7\% (36/183) of water specimens collected over an 18 months period from the Zhu River (the river passing through Guangzhou City) were NoVs positive. Homologous sequences were identified from river water, seafood, and AGE patients [45]. It has been suggested that NoVs shed from patients re-enter the river, float to coastal fishing areas downstream, where seafood is subsequently contaminated.

As for person-to-person transmission, NoVs could be detected on soap boxes $(63.6 \%, 7 / 11)$, handle of mops $(50.0 \%, 5 / 10)$, cups $(44.4 \%, 4 / 9)$, toilet-doors $(40.0 \%$, $2 / 5)$, toys $(22.2 \%, 2 / 9)$, water taps $(16.7 \%, 1 / 6)$, and tableware $(11.1 \%, 1 / 9)$ in two kindergartens during the outbreak [47]. Moreover, NoVs genomes were detected in air samples taken in 3 distinct locations on patient wards: (1) inside the room of patients with AGE symptoms $(<24$ h), (2) in the hallways or the common room outside of the rooms of patients with symptoms, and (3) at the nurses' station, where concentrations ranged from $1.35 \times 10^{1}$ to $2.35 \times 10^{3}$ genomes $/ \mathrm{m}^{3}$ in $47 \%$ of air samples [49].

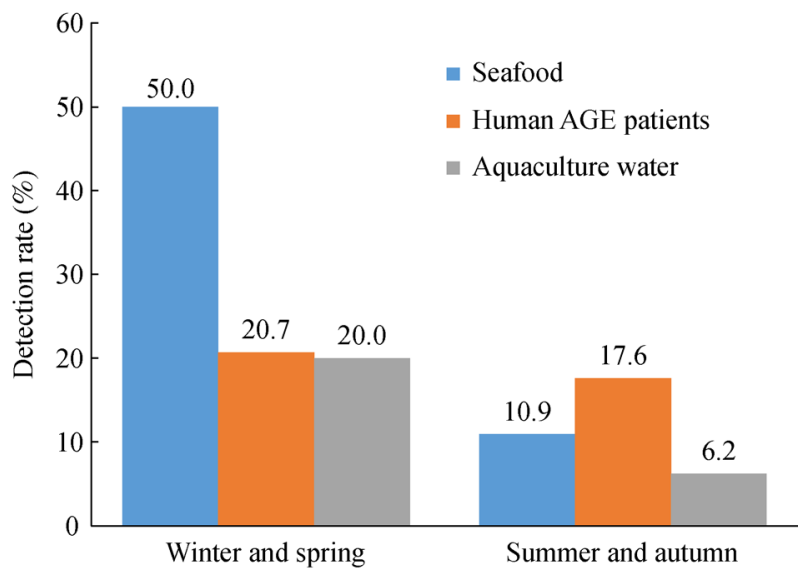

Fig. 1 The detection rates of norovirus from different sources by seasonality.

\section{Summary}

Similar to the occurrence and epidemiological characteristics of NoVs worldwide [2], NoVs also cause a considerable disease burden in China, especially in children $<2$ years and elderly $\geqslant 65$ years. Public awareness of NoV infections is increasing, due to frequent reports of outbreaks. Since NoVs are widespread in food supplies and environment in China, these potential vehicles might make NoV transmission ubiquitous. Given their highly infectious nature, propensity for causing outbreaks, primary environmental reservoir, and tolerance to physical and chemical substances, vaccination appears to be the most appropriate strategy to control NoV infections. Recently, two vaccine candidates, both based on the expression of NoV virus-like particles (VLPs), being composed of GI.1, GII.4 and GI.1, GII.3, GII.4, GII.17, respectively, have been approved for human trials in China. However, NoVs are antigenically diverse, and it is currently not known whether the cross-protection between genotypes exists. In addition, there is currently no well-established immunological surrogate to assess the potential efficacy of vaccine candidates. These challenges for vaccine development need to be addressed urgently to help control NoV infections.

\section{Acknowledgements}

This work was supported by grants from National Science and Technology Project of Major New Drug Discovery (No. 2018ZX09739002-006).

\section{Compliance with ethics guidelines}

Honglu Zhou, Songmei Wang, Lorenz von Seidlein, and Xuanyi Wang declare that they have no conflict of interest. This manuscript is a review article and does not involve a research protocol requiring approval by a relevant institutional review board or ethics committee.

Open Access This article is licensed under a Creative Commons Attribution 4.0 International License, which permits use, sharing, adaptation, distribution and reproduction in any medium or format, as long as you give appropriate credit to the original author(s) and the source, provide a link to the Creative Commons license, and indicate if changes were made.

The images or other third party material in this article are included in the article's Creative Commons license, unless indicated otherwise in a credit line to the material. If material is not included in the article's Creative Commons license and your intended use is not permitted by statutory regulation or exceeds the permitted use, you will need to obtain permission directly from the copyright holder.

To view a copy of this license, visit http://creativecommons.org/ licenses/by/4.0/. 


\section{References}

1. United Nations Inter-agency Group for Child Mortality Estimation (UN IGME). Levels and trends in child mortality: report 2017, Estimates Developed by the UN Inter-agency Group for Child Mortality Estimation. New York: United Nations Children's Fund, 2017

2. Ahmed SM, Hall AJ, Robinson AE, Verhoef L, Premkumar P, Parashar UD, Koopmans M, Lopman BA. Global prevalence of norovirus in cases of gastroenteritis: a systematic review and metaanalysis. Lancet Infect Dis 2014; 14(8): 725-730

3. Lopman BA, Steele D, Kirkwood CD, Parashar UD. The vast and varied global burden of norovirus: prospects for prevention and control. PLoS Med 2016; 13(4): e1001999

4. Siebenga JJ, Vennema H, Zheng DP, Vinjé J, Lee BE, Pang XL, Ho EC, Lim W, Choudekar A, Broor S, Halperin T, Rasool NB, Hewitt J, Greening GE, Jin M, Duan ZJ, Lucero Y, O’Ryan M, Hoehne M, Schreier E, Ratcliff RM, White PA, Iritani N, Reuter G, Koopmans $\mathrm{M}$. Norovirus illness is a global problem: emergence and spread of norovirus GII.4 variants, 2001-2007. J Infect Dis 2009; 200(5): 802-812

5. Hoa Tran TN, Trainor E, Nakagomi T, Cunliffe NA, Nakagomi O. Molecular epidemiology of noroviruses associated with acute sporadic gastroenteritis in children: global distribution of genogroups, genotypes and GII.4 variants. J Clin Virol 2013; 56(3): 269-277

6. Division of Infectious Disease Chinese Center for Disease Control and Prevention. National Data of Class A, B and C Communicable Diseases in December 2017. Dis Surveill (Ji Bing Jian Ce) 2018; 33 (1): 1 (in Chinese)

7. Zhang P, Zhang J. Surveillance on other infectious diarrheal diseases in China from 2014 to 2015. Chin J Epidemiol (Zhonghua Liu Xing Bing Xue Za Zhi) 2017; 38(4): 424-430 (in Chinese)

8. Zhou HL, Zhen SS, Wang JX, Zhang CJ, Qiu C, Wang SM, Jiang X, Wang XY. Burden of acute gastroenteritis caused by norovirus in China: a systematic review. J Infect 2017; 75(3): 216-224

9. Bull RA, White PA. Mechanisms of GII.4 norovirus evolution. Trends Microbiol 2011; 19(5): 233-240

10. Conley MJ, McElwee M, Azmi L, Gabrielsen M, Byron O, Goodfellow IG, Bhella D. Calicivirus VP2 forms a portal-like assembly following receptor engagement. Nature 2019; 565(7739): 377-381

11. Vinjé J. Advances in laboratory methods for detection and typing of norovirus. J Clin Microbiol 2015; 53(2): 373-381

12. Wyllie R, Hyams JS, Kay M. Pediatric Gastrointestinal and Liver Disease (Fourth Edition). Elsevier Saunders,USA. 2011. 405-408

13. Teunis PF, Sukhrie FH, Vennema H, Bogerman J, Beersma MF, Koopmans MP. Shedding of norovirus in symptomatic and asymptomatic infections. Epidemiol Infect 2015; 143(8): 17101717

14. Hall AJ. Noroviruses: the perfect human pathogens? J Infect Dis 2012; 205(11): 1622-1624

15. Patel MM, Hall AJ, Vinjé J, Parashar UD. Noroviruses: a comprehensive review. J Clin Virol 2009; 44(1): 1-8

16. Imhoff B, Morse D, Shiferaw B, Hawkins M, Vugia D, LanceParker S, Hadler J, Medus C, Kennedy M, Moore MR, Van Gilder T;
Emerging Infections Program FoodNet Working Group. Burden of self-reported acute diarrheal illness in FoodNet surveillance areas, 1998-1999. Clin Infect Dis 2004; 38(Suppl 3): S219-S226

17. Yu J, Ye C, Lai S, Zhu W, Zhang Z, Geng Q, Xue C, Yang W, Wu S, Hall AJ, Sun Q, Li Z. Incidence of norovirus-associated diarrhea, Shanghai, China, 2012-2013. Emerg Infect Dis 2017; 23(2): 312315

18. Wang JX, Zhou HL, Mo ZJ, Wang SM, Hao ZY, Li Y, Zhen SS, Zhang CJ, Zhang XJ, Ma JC, Qiu C, Zhao G, Jiang BM, Jiang X, Li RC, Zhao YL, Wang XY. Burden of viral gastroenteritis in children living in rural China: population-based surveillance. Int J Infect Dis 2019 October 28. [Epub ahead of print] doi:10.1016/j. ijid.2019.10.029

19. Yu J, Lai S, Wang X, Liao Q, Feng L, Ran L, Xu W, Qiu Y, Zhang Z, Li M, Wu J, Liu W, Yuan Z, Chen Y, Zhao S, Wang X, Zhao Z, Yu H, Jing H, Li Z, Yang W. Analysis of epidemiology characteristics of norovirus among diarrheal outpatients in 27 provinces in China, 2009-2013. Chin J Epidemiol (Zhonghua Liu Xing Bing Xue Za Zhi) 2015; 36(3): 199-204 (in Chinese)

20. Lian Y, Wu S, Luo L, Lv B, Liao Q, Li Z, Rainey JJ, Hall AJ, Ran L. Epidemiology of norovirus outbreaks reported to the Public Health Emergency Event Surveillance System, China, 2014-2017. Viruses 2019; 11(4): E342

21. Simmons K, Gambhir M, Leon J, Lopman B. Duration of immunity to norovirus gastroenteritis. Emerg Infect Dis 2013; 19(8): 12601267

22. Song XJ, Zhang J, Shi GQ. Epidemiological characteristics of acute gastroenteritis outbreaks caused by norovirus in China, 2000-2013. Dis Surveill (Ji Bing Jian Ce) 2017; 32(2): 127-131 (in Chinese)

23. Fan AP, Zhang AH, Lie J. Systematic evaluation of literatures on epidemiological characteristics of viral diarrhea outbreaks in China. Mod Prev Med (Xian Dai Yu Fang Yi Xue) 2016; 43(6): 965-978 (in Chinese)

24. Li JS, Deng AP, Mo YL, Li H, Sun LM. A Norovirus caused gastroenteritis outbreak in a nursing home in Guangdong. Dis Surveill (Ji Bing Jian Ce) 2015; 30(3): 242-244 (in Chinese)

25. Yi J, Wahl K, Sederdahl BK, Jerris RR, Kraft CS, McCracken C, Gillespie S, Anderson EJ, Kirby AE, Shane AL, Moe CL. Molecular epidemiology of norovirus in children and the elderly in Atlanta, Georgia, United States. J Med Virol 2016; 88(6): 961-970

26. Hall AJ, Lopman BA, Payne DC, Patel MM, Gastañaduy PA, Vinjé J, Parashar UD. Norovirus disease in the United States. Emerg Infect Dis 2013 ; 19(8): 1198-1205

27. Shanghai Municipal Statistics Bureau, Survey Office of the National Bureau of Statistics in Shanghai. 2018 Shanghai Statistical Yearbook. Beijing: China Statistics Press, 2018

28. Corwin AL, Soderquist R, Edwards M, White A, Beecham J, Mills P, Larasati RP, Subekti D, Ansari T, Burans J, Oyofo B. Shipboard impact of a probable Norwalk virus outbreak from coastal Japan. Am J Trop Med Hyg 1999; 61(6): 898-903

29. Bailey MS, Gallimore CI, Lines LD, Green AD, Lopman BA, Gray JJ, Brown DW. Viral gastroenteritis outbreaks in deployed British troops during 2002-7. J R Army Med Corps 2008; 154(3): 156-159

30. Mayet A, Andreo V, Bedubourg G, Victorion S, Plantec J, Soullie B, Meynard J, Dedieu J, Polveche P, Migliani R. Food-borne outbreak of norovirus infection in a French military parachuting unit, April 2011. Euro Surveill 2011; 16(30): pii.19930 
31. Neo FJX, Loh JJP, Ting P, Yeo WX, Gao CQH, Lee VJM, Tan BH, $\mathrm{Ng}$ CG. Outbreak of caliciviruses in the Singapore military, 2015. BMC Infect Dis 2017; 17(1): 719

32. Yang WX, Shi HD, Yao L, Wang XL, Shen H, Shen QJ, Song LL, He XB. Prevention and treatment of an norovirus outbreak in a military base. Mil Med J Southeast Chin (Dong Nan Guo Fang Yi Yao) 2019; 21(1): 87-88 (in Chinese)

33. Wang P, Goggins WB, Chan EYY. A time-series study of the association of rainfall, relative humidity and ambient temperature with hospitalizations for rotavirus and norovirus infection among children in Hong Kong. Sci Total Environ 2018; 643: 414-422

34. Robilotti E, Deresinski S, Pinsky BA. Norovirus. Clin Microbiol Rev 2015; 28(1): 134-164

35. Sang SW, Zhao ZT, Suo JJ, Xing YB, Jia N, Gao Y, Du MM, Xie LJ, Deng CY, Ren SW, Liu YX. Characteristics of outbreak and epidmeiology of norovirus gastroenteritis in China. Chin J Nosocomiology (Zhong Hua Yi Yuan Gan Ran Xue Za Zhi) 2011; 21(20): 4245-4247 (in Chinese)

36. Qiao N, Ren H, Liu L. Genomic diversity and phylogeography of norovirus in China. BMC Med Genomics 2017; 10(Suppl 3): 51

37. Qiao N, Wang XY, Liu L. Temporal evolutionary dynamics of norovirus GII.4 variants in China between 2004 and 2015. PLoS One 2016; 11(9): e0163166

38. Ao Y, Wang J, Ling H, He Y, Dong X, Wang X, Peng J, Zhang H, Jin M, Duan Z. Norovirus GII.P16/GII.2-associated gastroenteritis, China, 2016. Emerg Infect Dis 2017; 23(7): 1172-1175

39. Kwok K, Niendorf S, Lee N, Hung TN, Chan LY, Jacobsen S, Nelson EAS, Leung TF, Lai RWM, Chan PKS, Chan MCW. Increased detection of emergent recombinant norovirus GII.P16GII.2 strains in young adults, Hong Kong, China, 2016-2017. Emerg Infect Dis 2017; 23(11): 1852-1855

40. Ao YY, Cong X, Jin M, Sun XM, Wang JJ, Zhang Q, Song J, Yu JM, Cui J, Qi JX, Tian M, Duan ZJ. Genetic analysis of reemerging GII.P16-GII.2 noroviruses in 2016-2017 in China. J Infect Dis 2018; 218(1): 133-143

41. Lu J, Fang L, Sun L, Zeng H, Li Y, Zheng H, Wu S, Yang F, Song T, Lin J, Ke C, Zhang Y, Vinjé J, Li H. Association of GII.P16-GII.2 recombinant norovirus strain with increased norovirus outbreaks, Guangdong, China, 2016. Emerg Infect Dis 2017; 23(7): 11881190

42. Liang H, Jiang Q, Dai GW, Mo YL, Fang L, Li H, Wen J, Lin XQ, Hu ZK, Deng XL, Huang Q, Zhang YH. Survey on norovirus contamination in commercial oysters in Guangdong Province from 2011 to 2012. Chin J Food Hygi (Zhong Guo Shi Pin Wei Sheng Za Zhi) 2013; 25(4): 359-362 (in Chinese)

43. Ming H, Fan J, Wu L, Yue L, Gao X, Liang Y. Contamination of typical human enteric viruses in economic shellfish along the Chinese coast. Acta Microbiologica Sinica (Wei Sheng Wu Xue Bao) 2014; 54(1): 69-79 (in Chinese)

44. Wang Y, Yan X, Shi C, Zhang J. Monitoring and analysis of Norovirus in lettuce and strawberry from markets in Qinhuangdao. Food Safe Qual Detec Technol (Shi Pin An Quan Zhi Liang Jian Ce Xue Bao) 2018; 9(22): 6059-6063 (in Chinese)

45. Luo L, Wu XW, Liu YF, Li QY, Xie HP, Wu YJ, Li L, Jiang LY, Yang X. The molecular epidemiology characteristics of norovirus in environment and clinical samples in Guangzhou from 2009 to 2011. Chin J Prev Med (Zhonghua Yu Fang Yi Xue Za Zhi) 2013; 47(1): 40-43 (in Chinese)

46. Liu SS, Tao ZX, Wang ST, Zhou N, Lin XJ, Song YY, Xu AQ. Norovirus molecular epidmeiology based on environmental sewage surveillance. Chin J Virol (Bing Du Xue Bao) 2018; 34(3): 342-348 (in Chinese)

47. Chen TL, Deng XQ. Investigation of environmental sample virus contamination in the norovirus epidemic. Chin J Child Heal Care (Zhongguo Er Tong Bao Jian Za Zhi) 2018; 26(8): 921-923 (in Chinese)

48. Wang AN, Zhong XW, Qin L, Wang Z, Chen RF, Lin H, Huang Q, Zhang YH. Circulation routes of norovirus among population and environment in coastal area. S China J Prev Med 2016; 42(2): 101107

49. Bonifait L, Charlebois R, Vimont A, Turgeon N, Veillette M, Longtin Y, Jean J, Duchaine C. Detection and quantification of airborne norovirus during outbreaks in healthcare facilities. Clin Infect Dis 2015; 61(3): 299-304 